\title{
Optical bonding with fast sol-gel
}

\section{Raz Gvishi \\ rgvishi@soreq.gov.il \\ Mariana Pokrass}

Galit Strum
Electro-optics Division, Soreq NRC, Yavne 81800, Israel.

Electro-optics Division, Soreq NRC, Yavne 81800, Israel.

Electro-optics Division, Soreq NRC, Yavne 81800, Israel.

We investigate here the properties of fast sol-gel for optical bonding. The precursors of the fast sol-gel material are organically modified alkoxides generating a transparent hybrid (organic-inorganic) substance with silica glass-like properties whose index of refraction can be modified by the addition of various metal-oxides. The fast sol-gel method consists of rapid fabrication of a viscous resin and its subsequent dilution for long shelf life use. This material, when used as an adhesive offers the option of either a thermal or UV curing procedure. We demonstrate a bonding strength of $\sim 10 \mathrm{MPa}$ when a $15 \mu \mathrm{m}$ layer is applied between two glass elements. The bonding remained stable after an extensive $-40^{\circ} \mathrm{C}-120^{\circ} \mathrm{C}$ temperature cycling with minimal residual solvent evaporation at $150^{\circ} \mathrm{C}$. The fast sol-gel material was tested for optical bonding between silica bulks, between silica bulk and silicon wafers and as an adhesive in silica fibre couplers. [DOI: 10.2971/jeos.2009.09026]

Keywords: optical bonding, sol-gel, ORMOSILs, refractive index, thermal stability

\section{INTRODUCTION}

Robust optical bonding is essential for advanced optical systems. Most optical adhesive materials that are in use today are based on organic constituents such as epoxy, UV-cured acrylic and silicone polymers, and suffer therefore from poor thermal and irradiation stability and limited transparency [1]-[4]. On the other hand, physical bonding methods such as optical contact bonding or diffusion bonding are stronger and more durable but require higher working temperatures, high-level surface flatness and cleanliness which make them impractical for many applications [5]-[9]. A novel approach to overcome this problem is to use sol-gel based materials which combine the thermal and optical power stability of inorganic materials with the ease and flexibility of applying organic materials. The use of sol-gel based materials for adhesive bonding was already demonstrated in some studies [10]-[12] but with limited success. We present here an alternative bonding method, based on fast sol-gel, which successfully combines the simplicity of organic bonding materials with optical and physical properties of glass-like materials. This method provides high optical quality bonding with high thermal and irradiation power stability. The adhesive material is easy to process and its optical and physical properties can be adapted to specific requirements.

The sol-gel method is a well known process for preparing glass-like materials at low temperatures $\left(25^{\circ} \mathrm{C}-80^{\circ} \mathrm{C}\right)$ [13][15]. Using the sol-gel technique thin films can be fabricated with refractive indices over a broad range $(1.2-2.0)$. Sol-gel materials with high refractive indices $(>1.46)$ can be obtained by manufacturing a silica skeleton with higher refractive in- dex additives, such as metal oxides (alumina, titania, zirconia etc.). In this case the increase in the refractive index is a linear function of the additives concentration [16]-[21]. Low refractive indices can be obtained by controlling the amount of porosity in the matrix $[22,23]$.

A drawback of preparing materials by the conventional solgel process (using only alkoxides as precursors) is the formation of cracks which limits the achievable bulk size to a few $\mathrm{cm}$, or the achievable film thickness to $<1 \mu \mathrm{m}[24,25]$. The fast sol-gel method allows preparation of crack-free bulks or films without shrinkage and with low residual organic content $(\sim 20 \mathrm{wt} \%)$ in a relatively short process [26]-[28]. These materials exhibit excellent optical qualities, are thermally stable and have good adhesive properties. The fast sol-gel method uses a combination of organically modified alkoxides with traditional alkoxides as precursors, obtaining a final product which is an organic-inorganic hybrid with properties that vary from silicone rubber to silica glass. We have adapted this method for manufacturing optical bonding materials.

\section{METHODOLOGY}

A detailed description of the fast sol-gel method can be found in [26]-[28]. Briefly, sol-gel precursors (alkoxides and organically modified alkoxides) are mixed and undergo hydrolysis and condensation. The fast sol-gel reaction is performed at a temperature of about $100^{\circ} \mathrm{C}$ under time-varying pressure conditions (from several atmospheres to vacuum). In this way a 
viscous sol-gel resin is quickly produced which, after a fast and simple curing process, leads to the final glass-like product. However, for optical bonding applications a long shelf-life is required. By diluting the viscous sol-gel resin with an appropriate solvent shortly after preparation, the diluted material can be kept for several months as a solution until required for use. The diluents can be removed by moderate heating or evaporation. The bonding procedure consists of spreading a thin film of the material on each surface by using either a spinner, a dipping technique, or by spraying and applying pressure on the surfaces. The sol-gel layer is subsequently cured either thermally or by UV irradiation (see following Section 3).

The optical and physical characterization of the adhesive material was performed as follows; Thermo-gravimetric analyses (TGA) were conducted with three different commercial instruments; Pyres-1 by (Perkin Elmer), SDT 2960 (TA Instruments), and SDTA 851 (Mettler-Toledo). Two kinds of measurements were done; fast scanning $\left(50^{\circ} \mathrm{C} /\right.$ minute) up to $400^{\circ} \mathrm{C}$ and slow scanning $\left(10^{\circ} \mathrm{C} /\right.$ minute) up to $150^{\circ} \mathrm{C}$ with dwell time of one hour at $150^{\circ} \mathrm{C}$. The optical UV-NIR transmission spectrum was measured with a Jasco model V-570 spectrometer and the IR transmission spectrum with Bruker model Vertex 70 FTIR spectrometer. Refractive index at $589 \mathrm{~nm}$ was measured with an Abbe Refractometer, Kruss AR-4D (resolution $\pm 0.001)$. Viscosity was measured with a Brookfield Viscometer, model LVD1. Temperature cycling tests were conducted with a homemade system consisting of a cell heated by a hot plate and cooled by liquid nitrogen, controlled by Eurotherm controller allowing temperature changes in the range $-40^{\circ} \mathrm{C}-120^{\circ} \mathrm{C}$. Adhesive tensile strength was measured using Cometech Material Testing Machine, model QC-506B1. Samples were analyzed and photographed using either by Leica Optical Microscope or simple digital camera.

\section{CURING}

The fast sol-gel method requires only a simple curing process. After a short preparation time (about 15 minutes) the hydrolysis and condensation reactions are completed and a viscous resin with about only $4 \%$ residual liquid is obtained. Therefore, just a short time of low temperature curing $\left(<100^{\circ} \mathrm{C}\right)$ is required to achieve complete residual liquid evacuation and full solidification. Due to the additional flexible organic tails in the silica skeleton of the fast sol-gel, stresses are released, crack formation is avoided and crack-free bulk monoliths or films are produced. We studied the thermal curing process using FTIR spectroscopy. The measurements were performed with thin sol-gel films coated on silicon substrate in order to overcome the strong absorption in this range, (400 $4000 \mathrm{~cm}^{-1}$ ). Figure 1 presents the FTIR spectrum as a function of thermal curing time for a sample with $18 \mathrm{wt} \%$ organic residuals. The spectrum is divided into two absorption ranges, 400 - $1800 \mathrm{~cm}^{-1}$ (a) and $2500-4000 \mathrm{~cm}^{-1}$ (b). An increase in the transmission at $3400 \mathrm{~cm}^{-1}$ and at $900 \mathrm{~cm}^{-1}$ as function of thermal-curing time was observed, corresponding to $\mathrm{OH}$ stretching [29, 30] and Si-OH bending [29]-[31] modes respectively. This increase is representative of the progress of the polymerization process. The decline of the peaks at $3400 \mathrm{~cm}^{-1}$ and $900 \mathrm{~cm}^{-1}$ halted after 24 hours indicating that the poly-
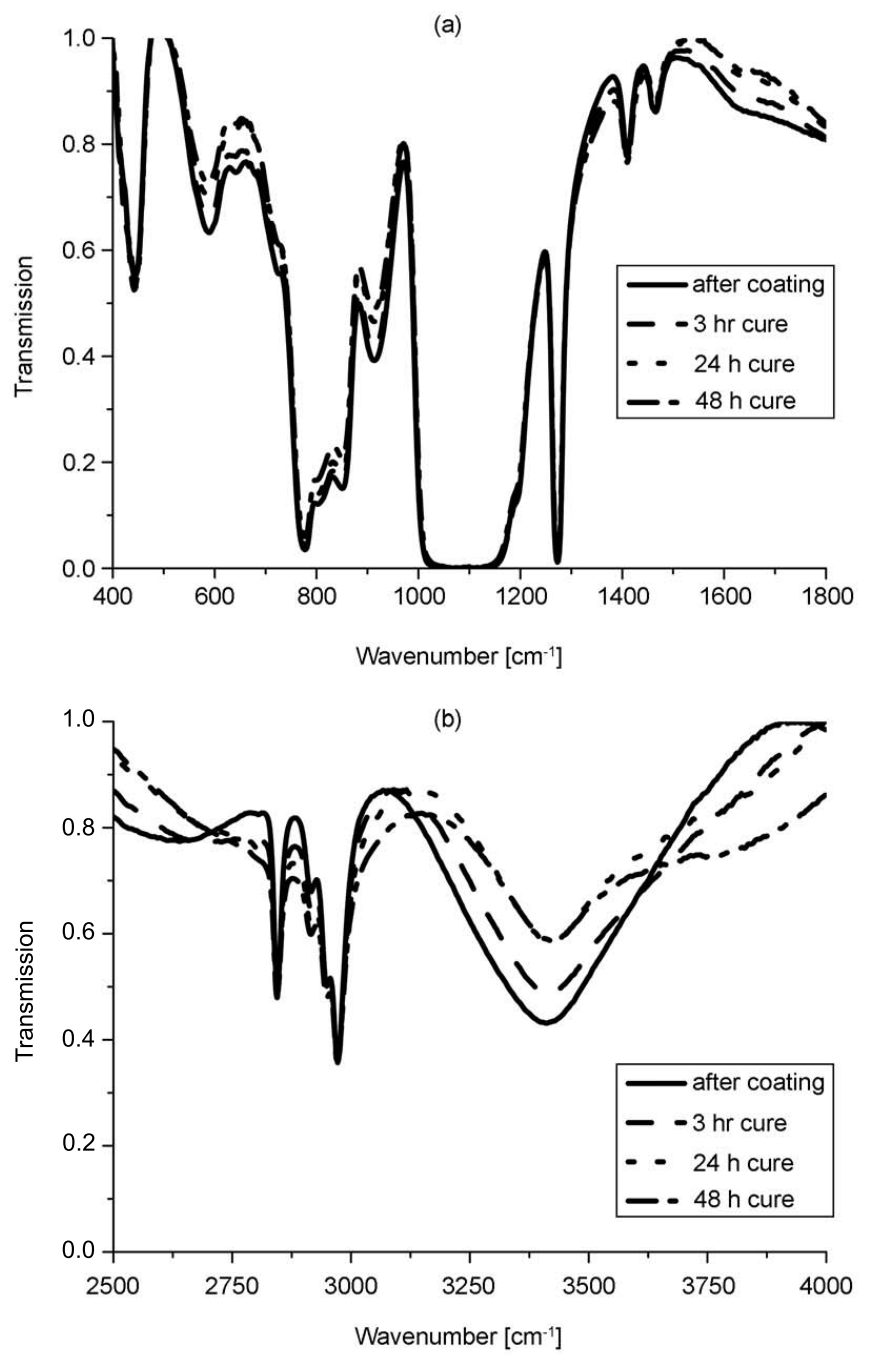

FIG. 1 FTIR transmission of fast sol-gel at different thermal-curing times with 18 wt\% organic residuals, in two absorption regions, $400-1800 \mathrm{~cm}^{-1}$ (a) and $2500-4000$ $\mathrm{cm}^{-1}$ (b).

merization was completed. The left residue at $3400 \mathrm{~cm}^{-1}$ and $900 \mathrm{~cm}^{-1}$ is due to surface $\mathrm{Si}-\mathrm{OH}$ groups and can be completely removed only at high temperature [32].

Some applications in electro-optics require a shorter curing procedure, where UV-curing techniques are applied. These techniques are very common and well established in optical bonding and photo-lithography. During the last decade, UV-curing of sol-gel materials with high content of organic residual was demonstrated and applied using organic modified silicates (ORMOSILs) of the class organic modified ceramics (ORMOCERs) [33]-[38] and epoxy based hybrids [39, 40]. Here we demonstrate the capability of UV-curing of low content organic residuals fast sol-gel material. To enable UVcuring, a photo-initiator for initiation of the polymerization process, is added to the fast sol-gel material with the diluter solution. This sol-gel solution was coated on a silicon substrate using a spin coating technique, followed by few seconds UV exposure through a lithographic mask, and washing the un-polymerized section using a developer. Figure 2 presents fast sol-gel stripe patterns on silicon substrate prepared by UV-curing technique. The obtained thickness (varying between $1-30 \mu \mathrm{m}$ ) is only dependent on the viscosity of the resin and on the speed of the spinner. Samples ranging 


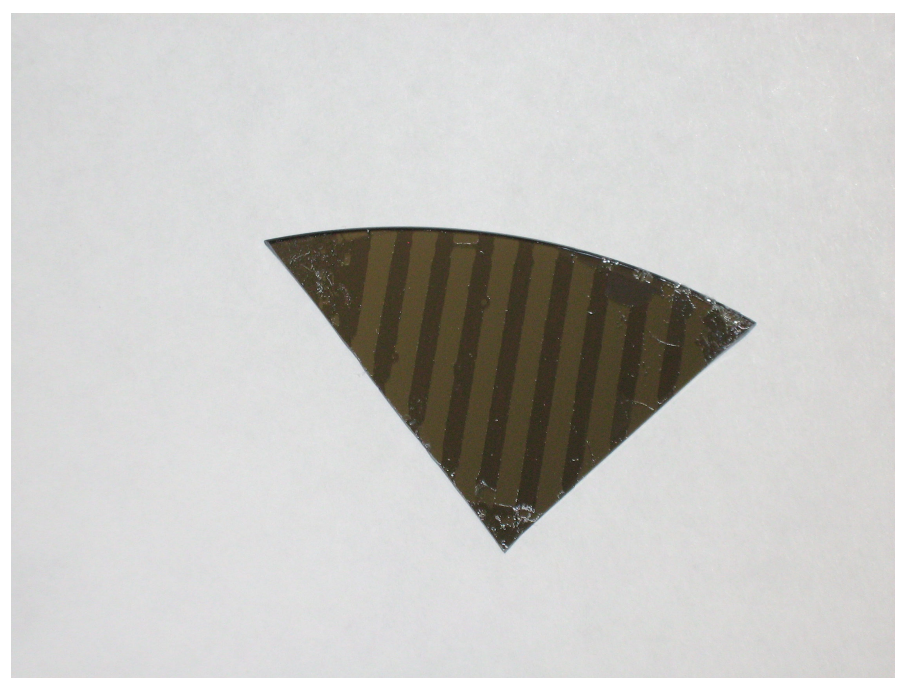

FIG. 2 Fast sol-gel stripe pattern (bright stripes) on silicon substrate (dark stripes) prepared by UV-curing technique.

from sub-micron up to several hundreds microns can be prepared in this way.

Figure 3 presents the FTIR spectrum as a function of UVcuring time. The increase in transmission is observed at $3400 \mathrm{~cm}^{-1}$ and at $900 \mathrm{~cm}^{-1}$ and at $1180 \mathrm{~cm}^{-1}$ (corresponding to $\mathrm{Si}-\mathrm{O}-\mathrm{CH}_{3}$ ). These spectra reveal that the polymerization is already completed after 60 seconds.

\section{PHYSICAL PROPERTIES}

The optical properties of the fast sol-gel material can be found in [26]-[28]. The fast sol-gel bonding material presents excellent optical transmittance in the visible range $(400-1100 \mathrm{~nm})$ with optical loss less than $0.05 \mathrm{~cm}^{-1}$. There are some absorption peaks in the $1100-1700 \mathrm{~nm}$ range due to vibration of Si$\mathrm{O}, \mathrm{O}-\mathrm{H}$ bonds, and $\mathrm{C}-\mathrm{H}$ bonds with an optical loss less than $1 \mathrm{~cm}^{-1}$.

A major aspect of the optical bonding performance is the ability to match the refractive index of the bonding material to the optical components. The sol-gel's refractive index can be controlled as a linear function of added metal oxides such as alumina, titania or zirconia. Figure 4 shows the refractive index value as function of the amount of titania in the fast sol-gel. By controlling the refractive index of the bonding material we succeeded to match its refractive index to bonded fibres and were able to transfer several hundred watts from one fibre to the other with efficiency greater than $95 \%$.

Another important characteristic is the viscosity of the material. Each application will require its own optimal viscosity as an adhesive material. In order to avoid solidification of the fast sol-gel resin and to enable a long shelf life, a dilution procedure was developed [41]. A standard organic polar solvent was used for dilution to prevent full polymerization. The dilution was done shortly after preparation of the viscous sol-gel resin. The diluting solvent dissolves the sol-gel polymer particles and this suspension can be kept in a solution state for several months. In these suspensions one can achieve any re-

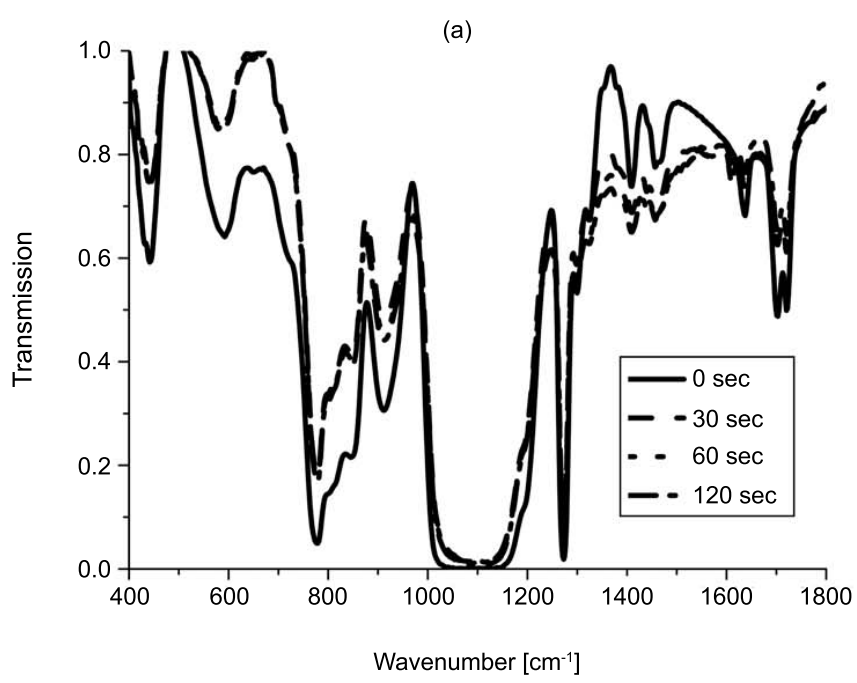

(b)

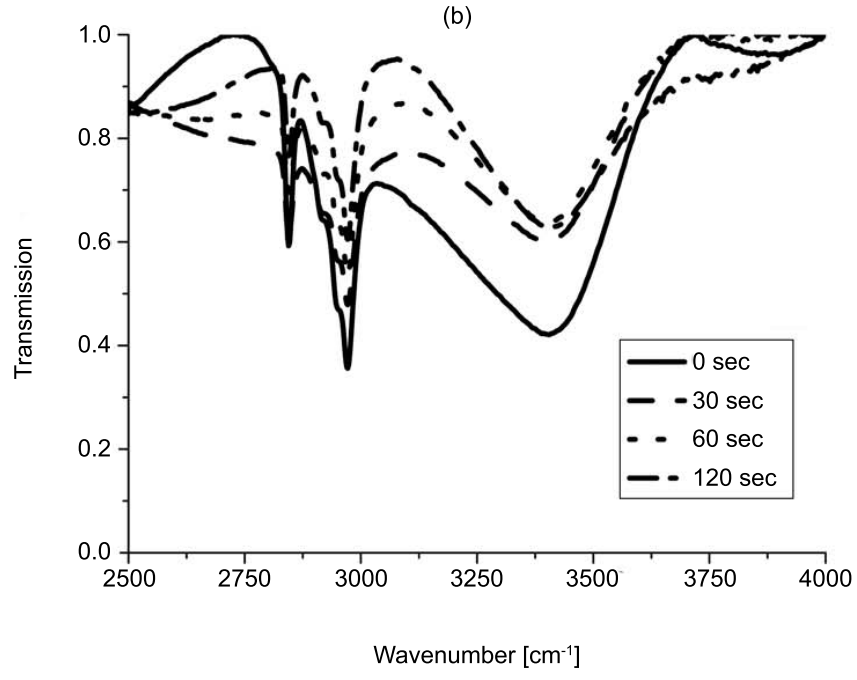

FIG. 3 FTIR transmission of fast sol-gel at different UV-curing times in two absorption regions, $400-1800 \mathrm{~cm}^{-1}$ (a) and $2500-4000 \mathrm{~cm}^{-1}$ (b).

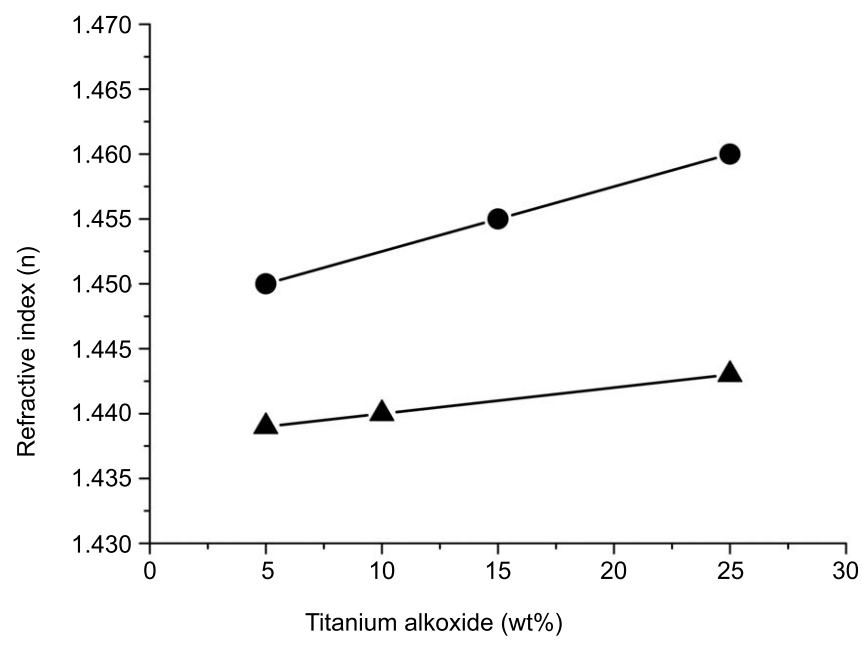

FIC. 4 Refractive index as a function of titanium alkoxide additive concentration (weight percentage of additive) for two types of titanium precursors (titanium butoxide - dot data, and titanium ethoxide - triangle data).

quired viscosity: from the viscosity of the diluter $(<1 \mathrm{cP})$ up to the pure high viscous resin $(>30,000 \mathrm{cP})$. The viscosity of the dilute resin as a function of solvent concentration is shown 

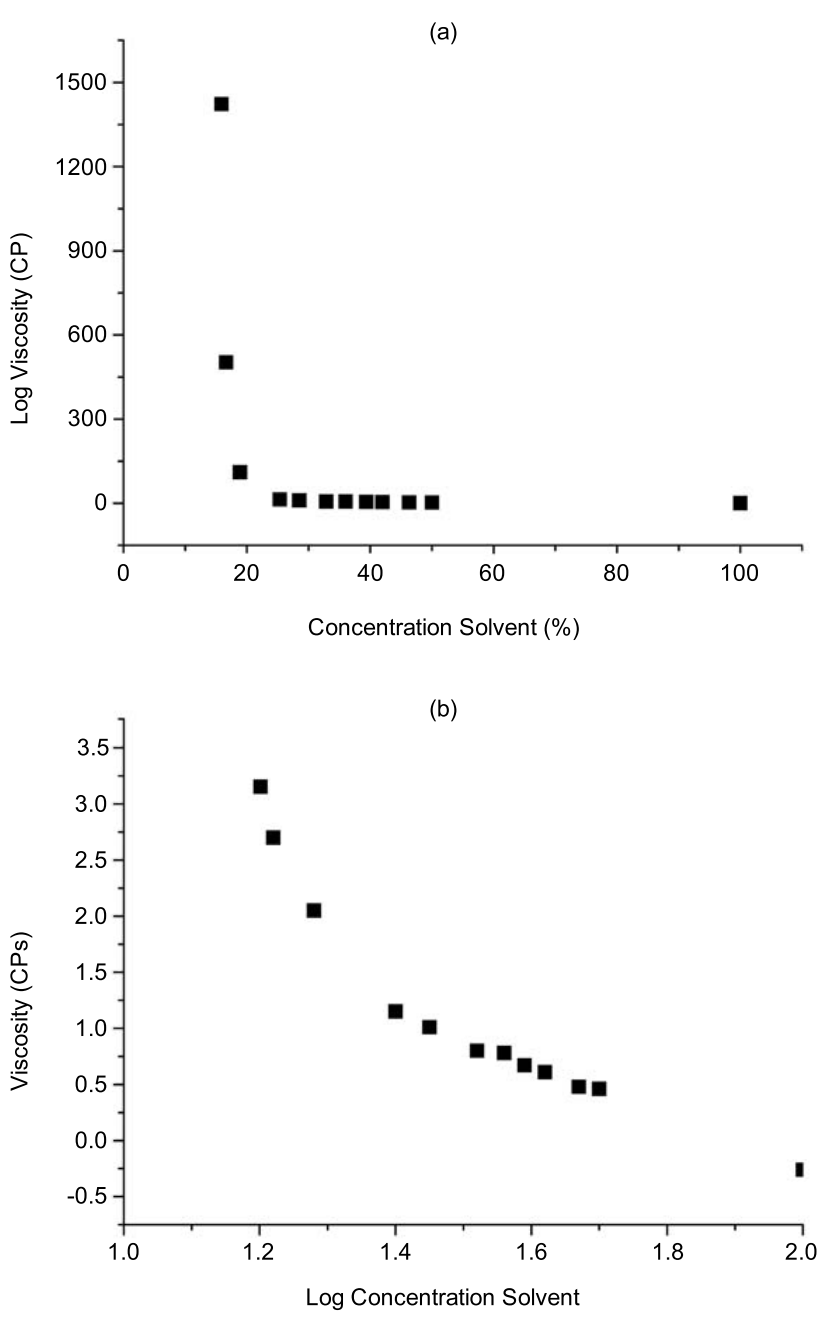

FIG. 5 Viscosity of the dilute material as function of the solvent concentration; (a) linear scale (b) logarithmic scale.

in Figure 5. After dilution, the sol-gel solution was easily filtered and did not polymerize for several months. The dilute material can be prepared for use for optical bonding by removal of the diluent by moderate heating or by solvent evacuation, until the appropriate viscosity is achieved.

An additional issue with optical bonding applications is the amount of residual volatile solvent left in the final product. The fast sol-gel final samples were tested using TGA to examine the weight loss due to evaporation of residual solvents [41]. The weight loss up to $150^{\circ} \mathrm{C}, 1 \%$, (shown in Figure 6) is due to water and alcohol evaporation and at higher temperatures, $4 \%$, is due to breaking off organics tails. These values are much lower than values reported for other sol-gel hybrid materials [42]-[44], demonstrating that by the fast sol-gel method very dry and stable final bulk monoliths or films can be fabricated in a short time.

\section{APPLICATIONS}

Optical bonding using the fast sol-gel material was demonstrated of bonding silica elements, of silica elements with silicon wafer, and as well in silica fiber couplers. In each case the bonding was tested for transmission efficiency after thermal cycles and for adhesive strength.

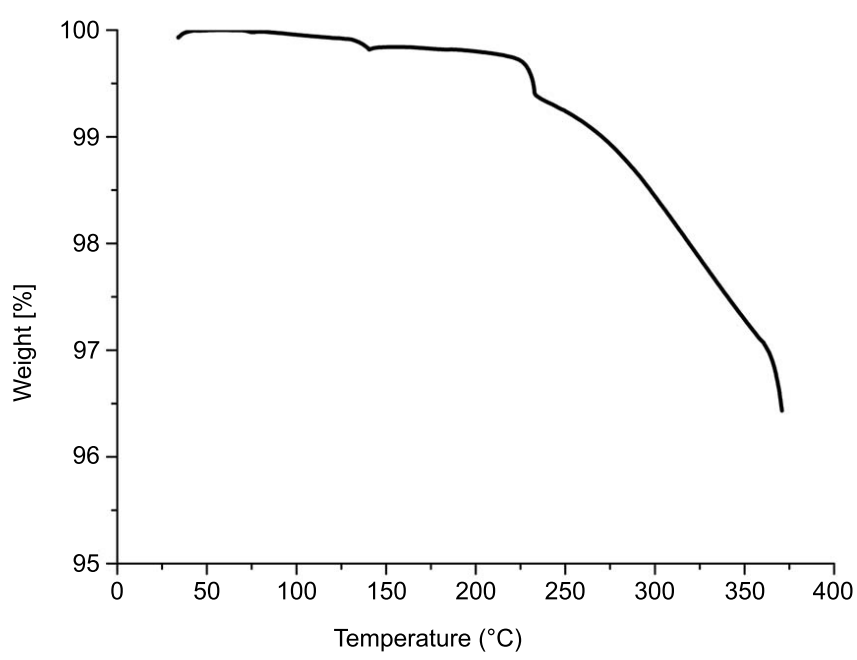

FIG. 6 TCA curve of fast sol-gel material for fast heating process up to $400^{\circ} \mathrm{C}$ observed a total weight loss of $4 \%$.

\subsection{Bonding of silica elements}

Two silica rectangular blocks each $17 \times 12 \times 6 \mathrm{~mm}$, were bonded using a fast sol-gel resin. The fast sol-gel material was applied by spinner on one surface of each block and, after removal of bubbles, the two elements were attached. A 24 hour thermal curing at $65^{\circ} \mathrm{C}$ was used. The bonding layer between the blocks can be controlled using the method of applying the resin, such as the spinner or by dipping. A $15 \mu \mathrm{m}$ thickness fast sol-gel layer produced strong optical bonding. Figure 7 presents a side view of two bonded silica blocks with a $15 \mu \mathrm{m}$ fast sol-gel bonding layer.

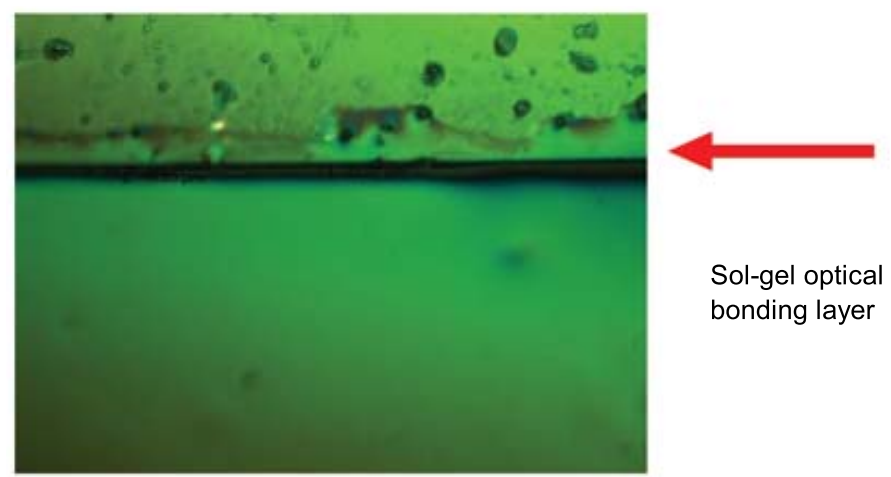

FIC. 7 Side view of two bonded silica blocks with $15 \mu \mathrm{m}$ fast sol-gel bonding layer with optical microscope.

The environmental stability of the bonding was tested by temperature cycling in the range $-40^{\circ} \mathrm{C}-+85^{\circ} \mathrm{C}$. The transmission spectrum which was measured afterward (shown in Figure 8) exhibits a clear transparency ( $>90 \%$, losses only due to surface reflections) over all the visible range from $300 \mathrm{~nm}$ up to 2,000 $\mathrm{nm}$. The absorption peaks at 1180, 1380 and $2280 \mathrm{~nm}$ are due to the inorganic residues of the silica precursors (water molecules $\mathrm{H}$-bonded to silanol groups and free silanol groups), and absorption peaks at 1680, 1730, 2350 and 2450 are due to the organic residues (absorption of organic tails groups).

A Cometech Material Testing Machine was used to test the adhesive strength of bonded slides with adhesive fast sol-gel 


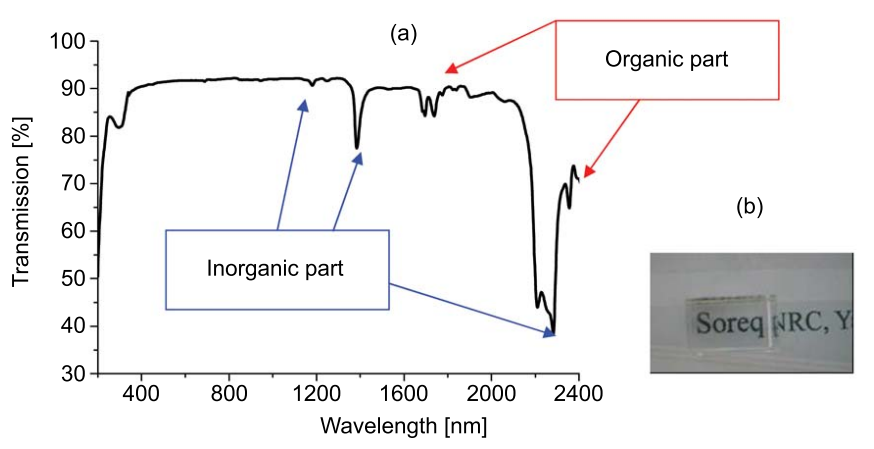

FIG. 8 Transmission spectra of two bonded silica elements with fast sol-gel adhesive layer (a) top view of two bonded silica rectangular blocks.

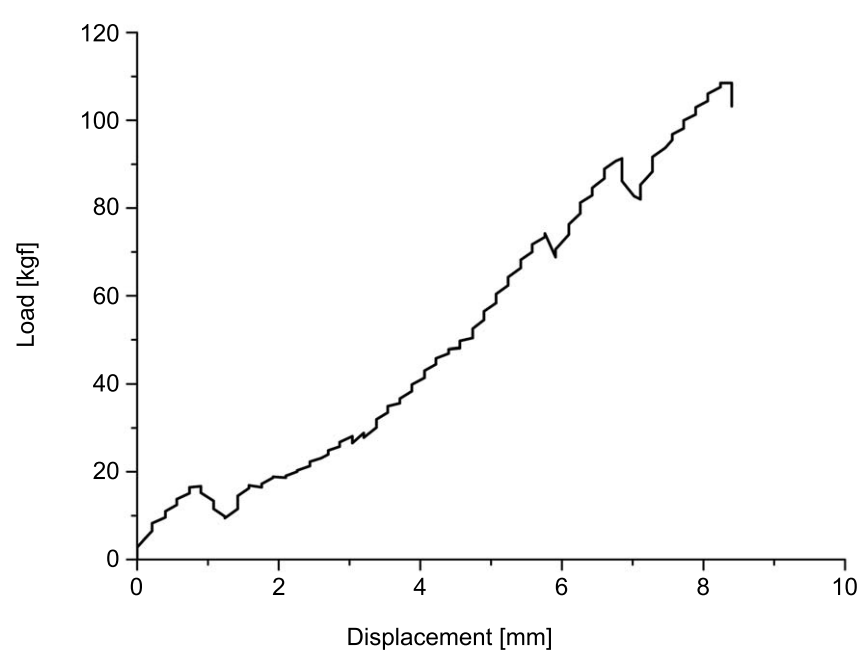

FIG. 9 The applied force as function of stretch length for silica bonded slides with fast sol-gel.

material. A Devecon 5 minutes Epoxy adhesive material with adhesive tensile lap shear of $13 \mathrm{MPa}$ was used as reference. Figure 9 shows the applied load force as function of stretch length. A value of at least $10 \mathrm{MPa}$ was observed for the fast sol-gel materials, at which value a failure in the slides was observed. The bonding area remained intact.

\subsection{Bonding between silica element and silicon wafer}

A system which combines transparent silica optical elements and semiconductor-based detectors requires the ability to directly bond the silica elements to the detector wafer. We have demonstrated such possibility by bonding a silica rectangular block to a silicon wafer in a procedure similar to the one presented in the previous section. In this case the samples were tested under temperature cycles in the range $-10^{\circ} \mathrm{C}-+120^{\circ} \mathrm{C}$ without obtaining any damage to the fast sol-gel bonding layer.

\subsection{Bonding of silica fibres}

Silica fibres were bonded in several configurations; tip to tip and side attachment, where the intermediate region is the fast sol-gel material. An adhesive strength of about $7 \mathrm{MPa}$ was found for tip to tip bonded fibres. With fibres, matching the refractive index of the optical bonding material to the fibre is essential for the highest transmission performance. By matching the refractive index of the fast sol-gel to the refractive index of fused silica fibres $(n=1.458)$ we observed more than 95\% transmission efficiency through the bonded fibres with irradiation of several hundred Watts. The bonded fibres environmental stability was tested by temperature cycling in the range $-40^{\circ} \mathrm{C}-+85^{\circ} \mathrm{C}$ without change in the transmission efficiency. In addition the bonded fibres withstand $5 \mathrm{~kW} / \mathrm{cm}^{2}$ light radiation without decrease in transmission.

\section{CONCLUSION}

A sol-gel hybrid organic/inorganic with a low organic content $(\sim 20 \mathrm{wt} \%)$ and controllable refractive index was developed for strong optical bonding. It exhibits excellent optical properties with glass-like mechanical characteristics. Due to the low organic content the dominant properties are glass-like, allowing the material to withstand high temperatures and high light power. The fast sol-gel material was proven to be useful for optical bonding of silica elements, silica elements to silicon wafers and silica fibres. It was tested under temperature cycles in the range $-40^{\circ} \mathrm{C}$ up to $120^{\circ} \mathrm{C}$ and several hundred Watts illumination $\left(5 \mathrm{~kW} / \mathrm{cm}^{2}\right)$, without causing any damage to the bonding, while retaining transmission efficiency of $\sim 95 \%$.

\section{ACKNOWELEDGMENTS}

We would like to give acknowledgments to D. Golodnitsky, Tel Aviv University and Z. Shemes, NRCN for TGA measurements and to Y. Sintov, Soreq for fibre coupler data.

\section{References}

[1] F. Twyman, Prism and Lens making $2^{\text {nd }}$ ed. (Hilger a Watts, London, 1952).

[2] J. R. Wimperis and S. F. Johnston, "Optical cements for interferometric applications" Appl. Opt. 23, 1145 (1984).

[3] C. Park, S. Lee, J. H. Lee, J. Lim, S. G. Lee, M. Park, S. S. Lee, J. Kim, C. R. Park, and C. Kim, "Controlled assembly of carbon nanotubes encapsulated with amphiphilic block copolymer" Carbon 45, 2072 (2007).

[4] H. Zhao, Z. Fu, Y. X. Wu, and Y. Z. Zhao, "Design and implementation of an auto bonding manufacturing process for space solar cells" Mater. Manuf. Process. 22, 851 (2007).

[5] J. Haisma and G. A. Spierings, "Contact bonding, including directbonding in a historical and recent context of materials science and technology, physics and chemistry: Historical review in a broader scope and comparative outlook" Mat. Sci. Eng. R. 37, 1 (2002).

[6] 0. M. Akelsen, “Diffusion bonding of ceramics" J. Mater. Sci. 27, 569 (1992).

[7] A. Plossi and G. Krauter, "Wafer direct bonding: tailoring adhesion between brittle materials" Mat. Sci. Eng. R. 25, 1 (1999).

[8] V. Greco, F. Marchesini, and G. Molesini, “Optical contact and van der Waals interactions: the role of the surface topography in determining the bonding strength of thick glass plates" J. Opt. A-Pure Appl. 0p. 3, 85 (2001). 
[9] B. Rubinstein, S. M. Jackel, R. Feldman, and Y. Shimony, "Effect of interactivity diffusion-bonded optical elements on laser performance", Proc. SPIE 5460, 141 (2004).

[10] S. Sivasankar and S. Chu, "Optical Bonding Using silica nanoparticale sol-gel chemistry" Nano lett. 7, 3031 (2007).

[11] M. Keranen, M. Gnyba, P. Raerinne, T. Kololuoma, A. Maaninen, and J. T. Rantala, "Synthesis and Characterization of Optical SolGel Adhesive for Military Protective Polycarbonate Resin" J. Sol-Gel Sci. Techn. 31, 369 (2004).

[12] Boeing and Wright-Patterson Air Force base, "Sol-Gel adhesive bonding of metals - AC-130", US patent 5807430 (1998).

[13] L. C. Klein, Sol-Gel Technology For Thin Films, Performs, Electronics, and Specialty Shapes (Noyes, New Jersey, 1988).

[14] C. J. Brinker and G. W. Scherer, Sol-Gel Science: The Physics and Chemistry of Sol-Gel Processing (Academic Press, San Diego, 1990).

[15] L. C. Klein, Sol-Gel Optics: Processing and Applications (Kluwer Academic Publishers, Boston, 1993).

[16] Y. Sorek, R. Reisfeld, I. Finkelstein, and S. Ruschin, "Light amplification in a dye-doped glass planar waveguide" Appl. Phys. Lett. 66, 1169 (1995).

[17] W. Que, Y. Zhou, Y. L. Lam, Y. C. Chan, H. T. Tan, and C. H. Kam, "Sol-gel processed silica/titania/ÿ-Glycidoxypropyltrimethoxysilane composite materials for photonic applications" J. Electron. Mater. 29, 1052 (2000).

[18] W. Que, Y. Zhou, Y. L. Lam, Y. C. Chan, and C. H. Kam, “Optical and microstructural properties of sol-gel derived titania/organically modified silane thin films" Thin Solid Films 358, 16 (2000).

[19] P. Innocenzi, A. Martucci, M. Guglielmi, L. Armelao, S. Pelli, G. C. Righini, and G. C. Battaglin, "Optical and surface properties of inorganic and hybrid organic-inorganic silica-titania sol-gel planar waveguides" J. Non-Cryst. Solids 259, 182 (1999).

[20] C. C. Chang and W. C. Chen, "High-refractive-index thin films prepared from aminoalkoxysilane-capped pyromellitic dianhydridetitania hybrid materials" J. Polym. Sci. Pol. Chem. 39, 3419 (2001).

[21] L. H. Lee and W. C. Chen, "High-Refractive-Index Thin Films Prepared from Trialkoxysilane-Capped Poly(methyl methacrylate)Titania Materials" Chem. Mater. 13, 1137 (2001).

[22] M. Ojha, W. N. Gill, Plawsky, and W. Cho, "Fabrication of ultrathin $(\sim 100 n m)$, low-index nanoporous silica films for photonic devices: Role of substrate adhesion on the film thickness" J. Vac. Sci. Technol. B 24, 1109 (2006).

[23] B. S. Bae, "High Photosensitive Sol-Gel Hybrid Materials for Direct Photo-Imprinting of Micro-Optics" J. Sol-Gel Sci. Techn. 31, 309 (2004).

[24] H. Dislich, "Thin films from the sol-gel process" in Sol-Gel technology for thin films, fibers, preforms, electronics, and specialty shapes, L. C. Klein, ed., Chapter 4 (Noyes, New Jersey, 1988).

[25] R. Gvishi and R. Reisfeld, "Spectroscopy of laser dye oxazine-170 in sol-gel glasses" J. Non-Cryst. Solids 128, 69 (1991).

[26] R. Gvishi, G. Strum, N. Shitrit, and R. Dror, "Optical waveguide fabrication using a fast sol-gel method" Opt. Mater. 30, 1755 (2008).

[27] R. Gvishi, A. Englander, and G. Peleg, "Multi-parameter evaluation of fast sol-gel process by terahertz measurements" J. Sol-Gel Sci. Techn. 48, 18 (2008).

[28] R. Gvishi, "Fast sol-gel from fabrication to applications" J. Sol-Gel Sci. Techn. 50, 241 (2008).
[29] N. B. Cothup, L. H. Daly, and S. E. Wiberley, Introduction to Infrared and Raman Spectroscopy (Academic Press, New-York and London, 1964).

[30] A. Fidalgo and L. M. Ilharco, "The defect structure of sol-gelderived silica/polytetrahydrofuran hybrid films by FTIR" J. NonCryst. Solids 283, 144 (2000).

[31] J. Jabbour, S. Calas, S. Gatti, R. K. Kribich, M. Myara, G. Pille, P. Etienne, and Y. Moreau, "Characterization by IR spectroscopy of an hybrid sol-gel material used for photonic devices fabrication" J. Non-Cryst. Solids 354, 651 (2007).

[32] D. L. Ou and A. B. Seddon, "Near- and mid-infrared spectroscopy of sol-gel derived ormosils: vinyl and phenyl silicates" J. Non-Cryst. Solids 210, 187 (1997).

[33] U. Streppel, P. Dannberg, C. Waechter, A. Braeuer, L. Froehlich, R. Houbertz, and M. Popall, "New wafer-scale fabrication method stacked optical waveguide interconnects and 3D micro-optic structures using photoresponsive (inorganic-organic hybrid) polymers" Opt. Mater. 21, 475 (2002)

[34] R. Houbertz, G. Domann, C. Cronauer, A. Schmitt, H. Martin, J. U. Park, L. Froehlich, R. Buestrich, M. Popall, U. Streppel, P. Dannberg, C. Waechter, and A. Braeuer, "Inorganic-organic hybrid materials for application in optical devices" Thin Solid Films 442, 194 (2003).

[35] U. Haas, A. Haase, V. Satzinger, H. Pichler, G. Leising, G. Jakopic, B. Stadlober, R. Houbertz, G. Domann, and A. Schmitt, "Hybrid polymers as tunable and directly-patternable gate dielectrics in organic thin-film transistors" Phys. Rev. B 73, 235339 (2006).

[36] X. M. Du, T. Touam, L. Degachi, J. L. Guilbault, M. P. Andrews, and S. I. Najafi, "Sol-gel waveguide fabrication parameters: an experimental investigation" Opt. Eng. 37, 1101 (1998).

[37] P. Gupta, P. P. Markowicz, K. Baba, J. O'reilly, M. Samoc, and P. N. Prasad, "DNA-Ormocer based biocomposite for fabrication of photonic structures" Appl. Phys. Lett. 88, 213109 (2006).

[38] Y. H. Han, A. Taylor, M. D. Mantle, and K. M. Knowles, "UV-curing of organic-inorganic hybrid coating" J. Sol-Gel Sci. Techn. 43, 111 (2007).

[39] G. Brustatin, G. Della Giustina, M. Guglielmi, F. Romanato, P. Prosposito, M. Casalboni, and C. Palazzesi, Patternable hybrid solgel materials based on silica network modified with epoxy group, p. 75. (First Mediterranean Photonics Conference, Ischia, 25-28 June 2008).

[40] M. Guglielmi, M. G. Brusatin, and G. D. Giustina, "Hybrid glass-like films through sol-gel techniques" J. Non-Cryst. Solids 353, 1681 (2007).

[41] R. Gvishi, M. Pokrass, and G. Strum, Strong optical bonding with fast sol-gel material, p. 45. (First Mediterranean Photonics Conference, Ischia, 25-28 June 2008).

[42] S. Yan, J. Yin, J. Yang, and X. Chen, "Structural characteristics and thermal properties of plasticized poly(I-lactide)-silica nanocomposites synthesized by sol-gel method" Mater. Lett. 61, 2683 (2007).

[43] B. Li, Y. Hakuta, and H. Hayashi, "The synthesis of titanoniobate compound characteristic of various particle morphologies through a novel solvothermal route" Mater. Lett. 61, 3791 (2007).

[44] P. H. Perez, T. A. Ochoa, T. Viveros, and A. Montoya, "Influence of the Synthesis Method on the Properties of Ceria-Doped Alumina" J. Sol-Gel Sci. Techn. 37, 49 (2006). 